\title{
Pollution and Environmental Factors Effect on Calcification and Morphology of Mytilus galloprovincialis Shell from EI Jadida Coast (Atlantic Coast, Morocco)
}

\author{
Amine Khalil ${ }^{1}$, Jamila Sif ${ }^{1, *}$ and Mohamed Kabriti ${ }^{2}$ \\ ${ }^{I}$ Physiology and Ecotoxicology Team, Faculty of Sciences, Chouaib Doukkali University, \\ El Jadida 24000, Morocco \\ ${ }^{2}$ National Laboratory for Studies and Pollution Monitoring, Rabat, Morocco
}

('Corresponding author's e-mail: sif.jamila16@yahoo.com)

Received: 9 April 2021, Revised: 12 June 2021, Accepted: 19 June 2021

\begin{abstract}
The originality of the present work is to study, for the $1^{\text {st }}$ time, the existence of shell shape deformation in Mytilus galloprovincialis mussel from Morocco Atlantic coasts, in relation with local environmental parameters. A slight difference is noted in the average calcium concentrations between the 2 sites, with values of $10.02 \cdot 10^{-2} \pm 0.15 \mathrm{mM}$ and $10.3 \cdot 10^{-2} \pm 0.15 \mathrm{mM}$ respectively at Haouzia and JorfLasfar sites. A significant season al variation was observed in both sites, with the existence of 2 concentration peaks during the months of April and September. These results are correlated with the physicochemical records with the existence of a salinity gradient. Shell deformation was observed in 25.9 $\%$ of all individuals from Jorf-Lasfar site. These individuals (group 2) show a higher concentration of calcium ions in their shells, a reduced width and increased thickness.
\end{abstract}

Keywords: Shell deformation, Mytilus galloprovincialis, Calcium concentration, Climatic changes

\section{Introduction}

Now a day, the interest of the Mytilus galloprovincialis mussel in marine water quality monitoring programs is well established [1]. Actually, the feeding mode and the wide geographical distribution make this species an interesting biological material. The increase of anthropogenic pressure on marine ecosystems in general and on the Atlantic coastline of El Jadida region in particular prompted our research team to set up a local biomonitoring program, in order to assess the level of pollutants bioaccumulation [2-4] and to evaluate their effects on biological and physiological level $[5,6]$.

The observation of natural mussel beds during multiple sampling campaigns of Mytilus galloprovincialis has allowed us to detect anomalies in shell shape from Jorf-Lasfar site, which receives numerous industrial discharges. From the literature, scientists have noted the effect of abiotic parameters on the growth [7-9] and calcification of bivalve shells [10,11]. At low salinity, bivalves show reduced growth and calcification rates $[12,13]$ that are thought to be the result of increased energy expenditure for calcification, rather than osmotic stress [14]. Based on these data, we postulate that pollution and environmental factors has an effect on calcification and shell deformation in Mytilus galloprovincialis.

The aim of this study is to evaluate the effect of pollution on calcium rate and shell shape of Mytilus galloprovincialis mussel. During an annual cycle, calcium concentrations $\left[\mathrm{Ca}^{2+}\right]$ and morphometric measurements were recorded from individual's shells at Haouzia and Jorf-Lasfar site in El Jadida coast. The monitoring of environmental parameters was carried out simultaneously.

\section{Materials and methods}

\section{Study sites and sampling}

El Jadida region has experienced a very significant demographic and industrial boom in recent decades [15]. Numerous industrial units and urban expansions have been set up, generating a multiplication of effluents that are dumped into the sea. The threat to the coastline environment and its biodiversity is real. Two sites were chosen for this study: 


\section{Haouzia site}

Haouzia site is characterised by the presence of a rock substrate bordered on both sides by sand. The mussel bed is one of the most exploited in the area. One station was selected in this area.

\section{Jorf-Lasfar site}

Jorf-Lasfar site is located at $25 \mathrm{~km}$ southwest of El Jadida. Three stations were selected, at different distances from the industrial discharges of the area.

The stations placement is shown on Figure 1.

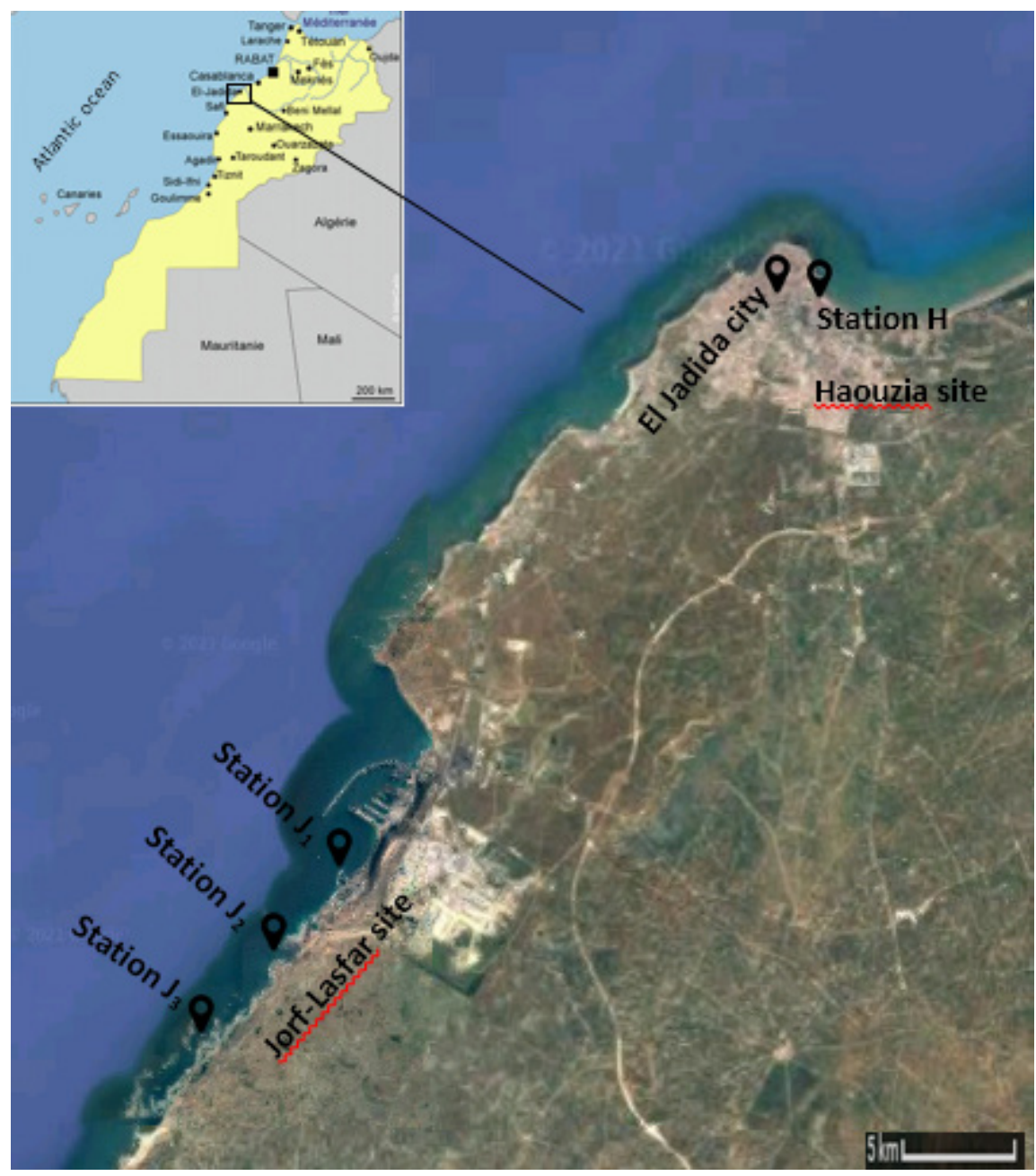

Figure 1 Location of the prospected stations (H: Haouzia site; $\mathrm{J}_{1}, \mathrm{~J}_{2}$ and $\mathrm{J}_{3}$ : Jorf-Lasfar site).

Mussels sampling was carried out at monthly bases at low tide in the intertidal zone. Once at the laboratory, the animals were cleaned and placed in oxygenated seawater for a purging period of 24 to 36 $\mathrm{h}$. The flesh was then extracted (for other experiments) and the shell valves were dried and stored properly until use.

\section{Physicochemical parameters measurements}

The following parameters: $\mathrm{pH}$, temperature, dissolved oxygen and salinity were measured on-site simultaneously during the sampling operation, using a multi-parameter measuring device (WTW, model Multi 340i). Calibration and cleaning of the probes were carried out as described in the user manual. 


\section{Calcium measurements}

Four mussel shells per station and per month were grinded with a mortar until a fine powder is obtained. Two $\mathrm{g}$ of this powder is placed in an Erlenmeyer flask with addition of $10 \mathrm{~mL}$ of hydrochloric acid (HCL 2M) to dissolve the sample. After filtration on filter paper, distilled water is added to the filtrate till completing $100 \mathrm{~mL}$ (Vi). A $20 \mathrm{~mL}$ of this initial solution is diluted to $100 \mathrm{~mL}$ with distilled water with addition of $10 \mathrm{~mL}$ of sodium hydroxide solution $(\mathrm{NaOH} 1 \mathrm{M})$ to obtain a basic mixture. This solution takes on a red-violet colour by adding a pinch of Murexide color indicator. The titration is carried out using Ethylene-Diamine-Tera-Acetic acid (E.D.T.A 2M) until the solution turns blue. The volume of EDTA $\left(\mathrm{V}_{\mathrm{EDTA}}\right)$ poured is used to calculate the calcium concentration $\left[\mathrm{Ca}^{+2}\right]$ in the shell sample:

$[C a+2]=(F d \times F c \times[E D T A] \times V E D T A) \div V i$

$\mathrm{F}_{\mathrm{d}}$ : Dilution factor.

$\mathrm{F}_{\mathrm{c}}$ : Correction factor obtained by dosing a standard solution of calcium carbonate.

This protocol uses the standard procedures of ISO 6058 [16]. Each measurement obtained is the average of 3 replicates. Throughout the assay, "blank" samples; containing no shell powder; are made up and undergo the same treatment as the experimental samples. The results are expressed in mM.

\section{Morphometric measurements}

Morphometric measurements were taken using a caliper of $1 / 20 \mathrm{~mm}$ accuracy. The measured parameters are (Figure 2):

1) Length: Represents the maximum distance between the anterior and posterior region of the shell (Figure 2(A)).

2) Width: Is the maximum distance between the ventral and dorsal faces of the valve (Figure 2(B)).

3) Thickness: Represents the maximum distance between the greater curvature of the shell valves (Figure 2(C)).

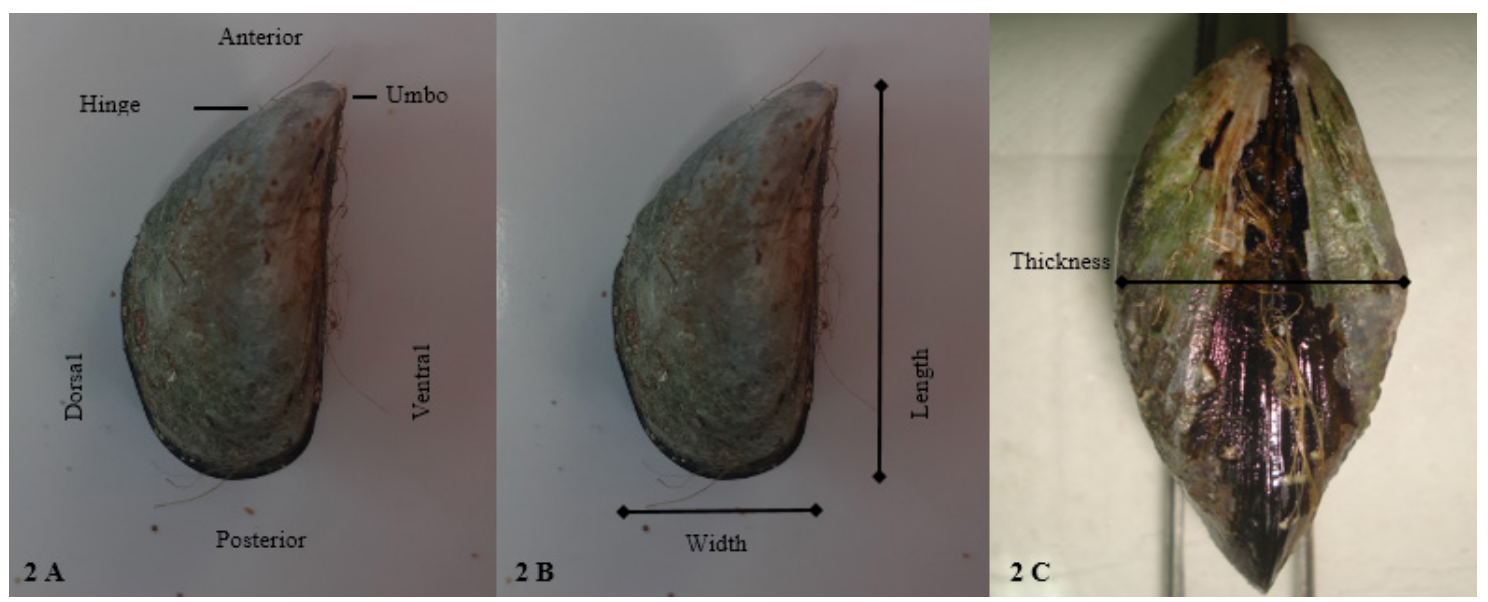

Figure 2 Morphometric measurements on Mytilus galloprovincialis shell: (A) Orientation of the outer side of the shell; (B) Shell length and width measurements and (C) Shell thickness measurement.

\section{Statistical analysis}

Both morphometric and $\left[\mathrm{Ca}^{+2}\right]$ are expressed as means \pm MSD. The comparison between morphometric measurements was done by ANOVA. Inter-station comparisons between the means of $\left[\mathrm{Ca}^{+2}\right]$ were performed by the non-parametric Wilcoxon test. Seasonal variations of $\left[\mathrm{Ca}^{2+}\right]$ were analysed by the Kruskal and Wallis test. The comparison of $\left[\mathrm{Ca}^{2+}\right]$ within $\mathrm{J}$ population was done using Man Whitney test. 


\section{Results and discussion}

\section{Results}

\section{Physicochemical parameters}

The water temperature shows distinct variations between the 2 sites. The highest values of around $21.4{ }^{\circ} \mathrm{C}$ were recorded during May in $\mathrm{H}$ and $\mathrm{J}_{1}$. In June, temperatures are $21{ }^{\circ} \mathrm{C}$ in $\mathrm{H}$ and $19.5{ }^{\circ} \mathrm{C}$ in $\mathrm{J}_{2}$. (Figure 3(A)). The pH values are between 7.1 and 8.2 (Figure 3(B)) at both sites. Water salinity at Haouzia site varies between 24 and 40.4 psu during respectively May and October. In Jorf-Lasfar site, the lowest values are 36.8 psu in May in station $\mathrm{J}_{1}$; the highest values are $46.6 \mathrm{psu}$ in December in $\mathrm{J}_{2}$ (Figure $3(\mathbf{C})$ ). Dissolved oxygen levels are $8.6 \mathrm{mg} / \mathrm{L}$ in $\mathrm{H}$ during January and $10.2 \mathrm{mg} / \mathrm{L}$ in $\mathrm{J}_{2}$ during March (Figure 3(D)) .

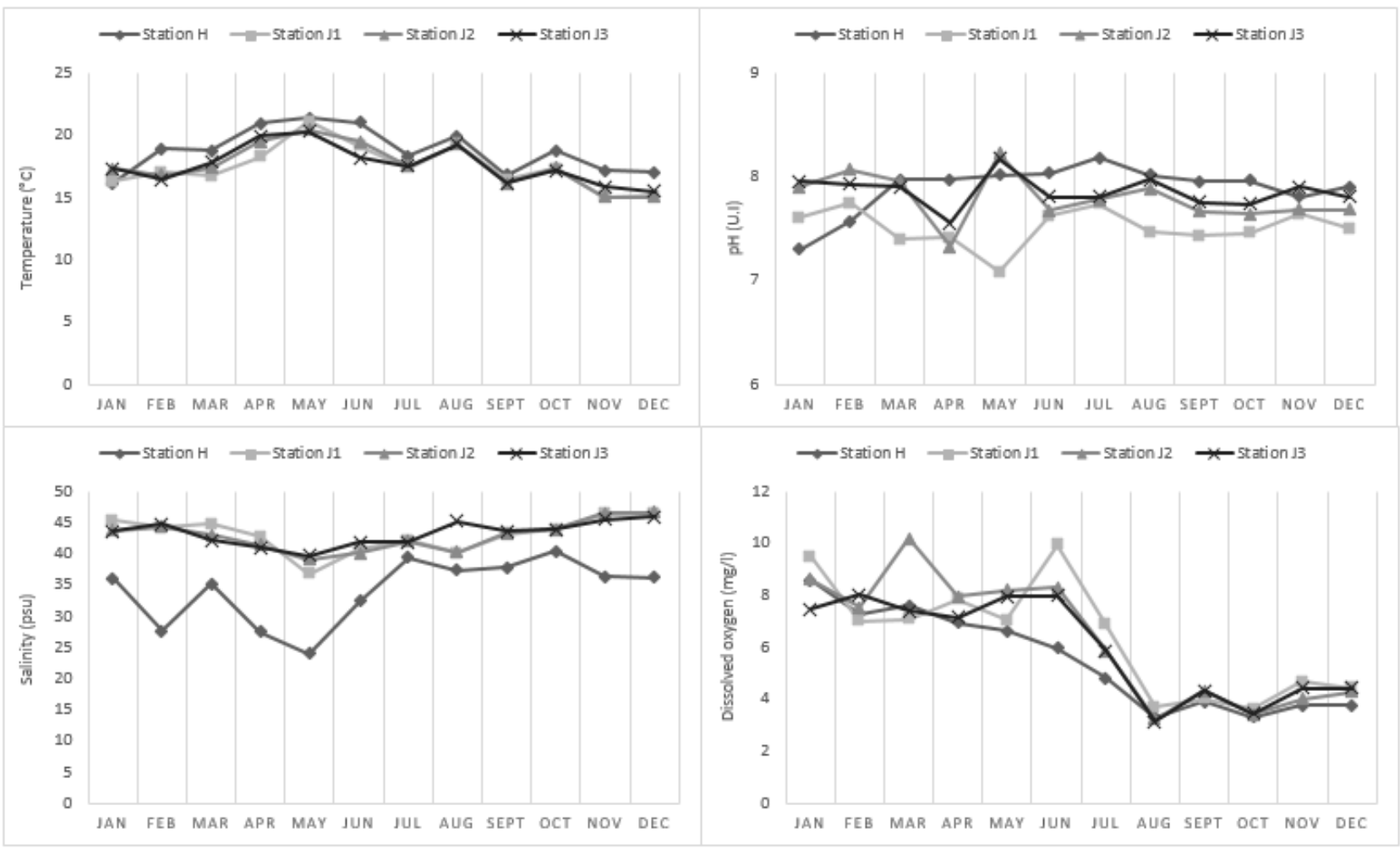

Figure 3 Environmental factors variations at prospected $\left(H, J_{1}, J_{2}\right.$ and $\left.J_{3}\right)$ from El Jadida coastline [6]: (A) Temperature variation; (B) $\mathrm{pH}$; (C) Salinity and (D) Dissolved oxygen.

\section{Calcium concentration}

Temporal variation of calcium concentration in mussel's shells is shown in Figure 4. In all stations, 2 peaks are distinguished during April and September. The calcium levels for the 2 peaks are respectively $11.84 \cdot 10^{-2}$ and $14.31 \cdot 10^{-2} \mathrm{mM}$ in the mussel's shells of station $\mathrm{H} ; 12.46 \cdot 10^{-2}$ and $14.12 \cdot 10^{-2} \mathrm{mM}$ in $\mathrm{J}_{1}$; $11.76 \cdot 10^{-2}$ and $14.12 \cdot 10^{-2} \mathrm{mM}$ in $\mathrm{J}_{2}$ and $12.16 \cdot 10^{-2}$ and $12.58 \cdot 10^{-2} \mathrm{mM}$ in $\mathrm{J}_{3}$. The lowest $\left[\mathrm{Ca}^{2+}\right]$ levels are recorded during January in individuals shells from $\mathrm{H}\left(6.8 \cdot 10^{-2} \mathrm{mM}\right)$ and $\mathrm{J}_{3}\left(7.58 \cdot 10^{-2} \mathrm{mM}\right)$, while in those of animals from $J_{1}$ and $J_{2}$ these levels are respectively $7.66 \cdot 10^{-2}$ and $7.88 \cdot 10^{-2} \mathrm{mM}$ during December. 


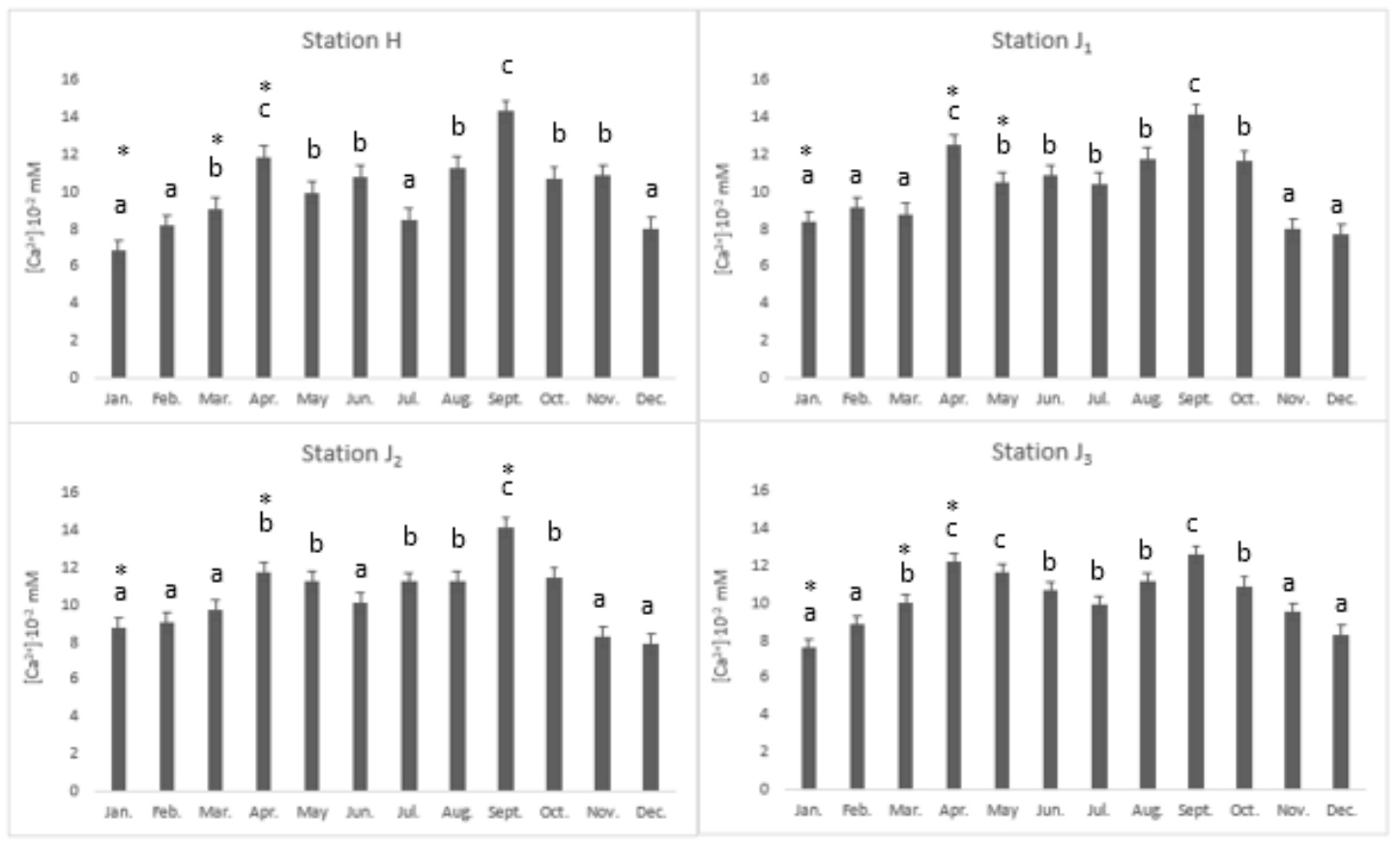

Figure 4 Monthly variations of calcium concentration in Mytilus galloprovincialis shell from the prospected stations. Histograms with "a", "b" and "c" letters on top are statistically different from each other. Histograms with the same letters are not statistically different. *: $p<0.05$.

Spatial variation of $[\mathrm{Ca} 2+]$ in mussel's shells is shown in Figure 5. No significant difference is observed between Haouzia and Jorf-Lasfar site.

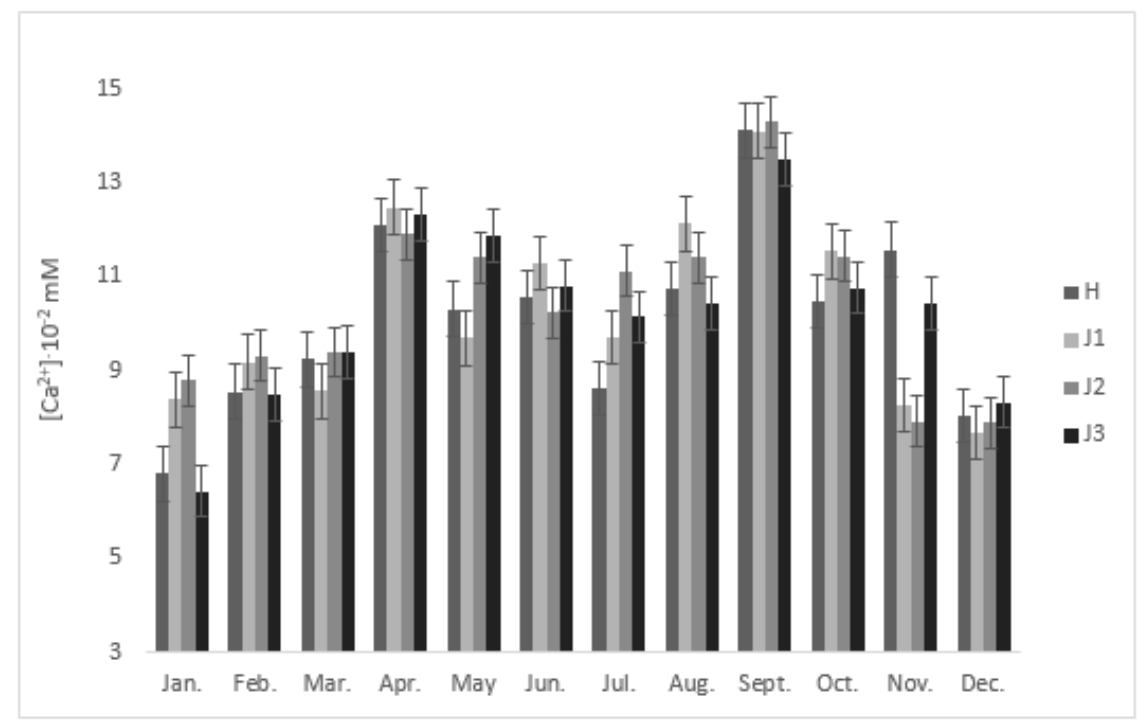

Figure 5 Spatial variation of $\left[\mathrm{Ca}^{+2}\right]$ in Mytilus galloprovincialis shell from prospected stations.

The comparison of the average calcium concentrations in individual's shells from the 4 stations is shown in Figure 6. The lowest average concentration is found in animals from station $\mathrm{H}$, with a value of $10.02 \cdot 10^{-2} \pm 0.15 \mathrm{mM}$ followed by individuals from station $\mathrm{J}_{3}$ with a value of $10.24 \cdot 10^{-2} \pm 0.15 \mathrm{mM}$. The highest levels were found in animals of $\mathrm{J}_{1}$ and $\mathrm{J}_{2}$, with values respectively of $10.28 \cdot 10^{-2} \pm 0.15$ and $10.38 \cdot 10^{-2} \pm 0.15 \mathrm{mM}$. 


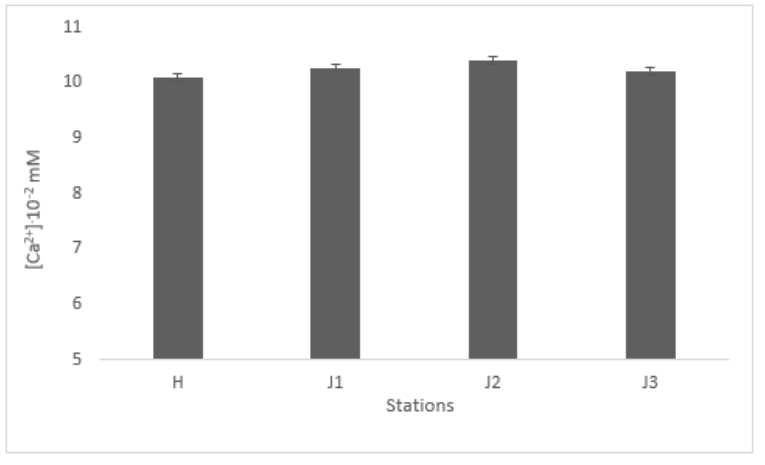

Figure 6 Average $\left[\mathrm{Ca}^{+2}\right]$ in Mytilus galloprovincialis shells from the prospected stations.

\section{Morphometric parameters}

During the sampling campaigns, observations concerning shells shape led us to differentiate 2 groups of animals. The $1^{\text {st }}$ one is made up of mussels with no shape anomaly (Group 1) and the $2^{\text {nd }}$ (Group 2) is made up of individuals with an external shell deformation (Figure 7). The deformation is whether localised on the ventral or dorsal side of the shells. All individuals of group 2 comes from JorfLasfar site and constitute $25.9 \%$.

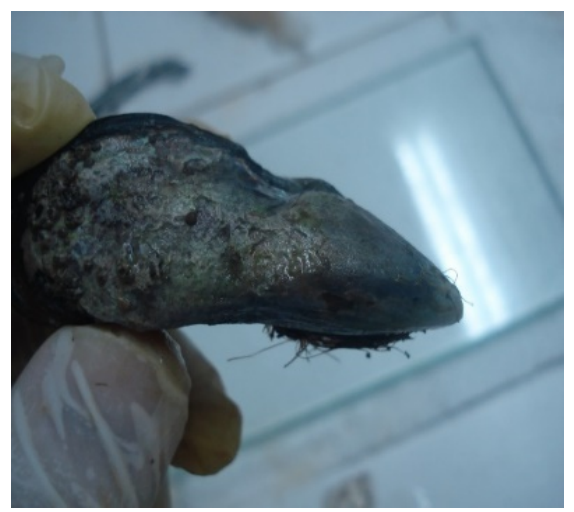

Figure 7 Illustration of shell deformation of Mytilus galloprovincialis from Jorf-Lasfar site.

The comparison of shell width and thickness (Figure 8) shows a statistically significant difference $(\mathrm{P}=0.03)$ between individuals in groups 1 and 2 . Indeed, individuals of group 1 have a mean width of $2.24 \pm 0.1 \mathrm{~cm}$, while those of group 2 have a mean width of $2.15 \pm 0.1 \mathrm{~cm}$. The measurement of shell thickness in both groups shows a highly significant difference $(\mathrm{P}=0.000007)$. Individuals of group 2 had an average shell thickness of $2.08 \pm 0.1 \mathrm{~cm}$ compared to $1.88 \pm 0.1 \mathrm{~cm}$ for those of group 1.

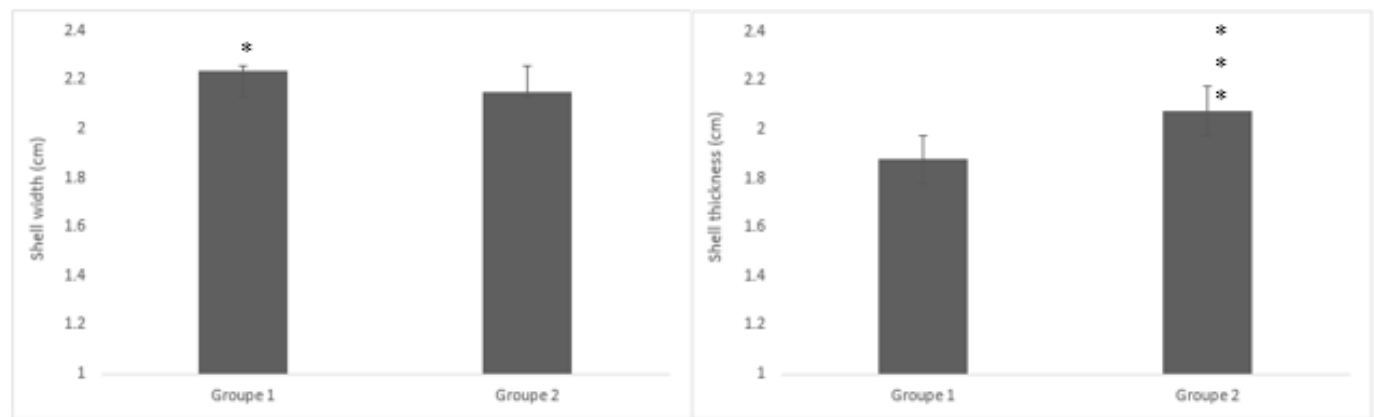

Figure 8 Comparison of shell width and thickness in individuals of groups 1 and 2 of Mytilus galloprovincialis mussel. Group 1: Without shell shape deformation. Group 2: $25.9 \%$ with shell shape deformation. $*: p<0.05 ; * * *: p<0.001$. 
The comparison of the average calcium concentrations between group 1 and group 2 is shown in Figure 9, and was done for autumn and winter seasons. Calcium concentration in individuals' shells of group 2 is higher than that of group 1 ; respectively $11.01 \cdot 10^{-2} \pm 0.12$ and $10.06 \cdot 10^{-2} \pm 0.15 \mathrm{mM}$. [Ca2+] level of individuals from Haouzia site is comparable to that of individuals from group 1, with a value of $10.2 \cdot 10^{-2} \pm 0.12 \mathrm{mM}$.

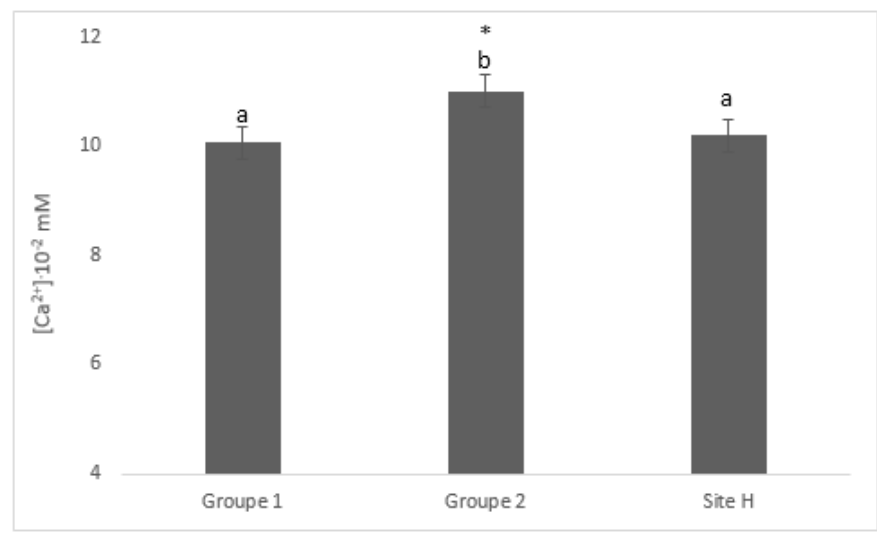

Figure 9 Comparison of $\left[\mathrm{Ca}^{+2}\right]$ in Mytilus galloprovincialis shell between individuals from group 1 and group 2 (Jorf-Lasfar site) and those from site H. Histograms with "a" and "b" letters on top are statistically different from each other. Histograms with the same letters are not statistically different. Group 1: Without shell shape deformation. Group 2: $25.9 \%$ with shell shape deformation. *: $p<0.05$.

\section{Discussion}

This study approach allowed us, for the $1^{\text {st }}$ time, to relate environmental factors to the appearance of shell deformations in the M. galloprovincialis mussel from the Atlantic coast of Morocco. In addition, the analytical aspect, through the quantification of shell calcium coupled with morphometric measurements, provides a new basis in understanding shell shape plasticity of this species. Calcium ions concentration in Mytillus galloprovincialis shell from the coast of El Jadida is slightly lower at Haouzia (H) site than JorfLasfar (J). These concentrations follows a seasonal variation which is well marked by 2 peaks, 1 in spring (April) and the $2^{\text {nd }}$ in early autumn (September). The shells of individuals collected in winter have the lowest $\left[\mathrm{Ca}^{+2}\right]$. Twenty-five percent $(25.9 \%)$ of the individuals from site $\mathrm{J}$ showed shell deformations. The morphometric parameters recorded confirm a significant gain in thickness. It is in this group of mussels (with shell deformations) that $\left[\mathrm{Ca}^{+2}\right]$ is the highest. The measurement of environmental parameters shows a salinity gradient between the 2 study sites.

Shell constitution in veliger larvae of bivalves begins $48 \mathrm{~h}$ after fertilisation $[17,18]$. In mytilids, natural variations in shell shape of Mytilus edulis and M. trossulu from the North Atlantic and the Arctic are generated by different environmental gradients of temperature, salinity and food availability [19]: 1) The effect of temperature gradient is thought to influence the metabolism of bivalves [20] and consequently has obvious effects on calcification of marine organisms under climate change [21,22]. 2) Osmotic stress caused by salinity gradients induces chemical changes in carbonates that are negatively affected by ocean acidification [23-25]. 3) The combined effects of decreasing $\left[\mathrm{Ca}^{2+}\right]$ and unfavourable carbonate chemistry in water represent limiting factors for calcification in bivalves [26,27].

In the present study, the monthly measurement of environmental parameters (salinity, temperature, $\mathrm{pH}$ and dissolved oxygen) of the water did not show big intra-site variations; except for salinity. However, we can explain the effect observed by the concomitance of multiple factors on the calcification of M. galloprovincialis shell. It is commonly accepted that osmotic stress, ocean acidification and temperature increase the impact on the shape and thickness of Mytilus shell [9-19]. Indeed, biomineralisation becomes successively more unfavourable due to the reduction of $\left[\mathrm{Ca}^{2+}\right]$ and inorganic dissolved carbon availability [25]. Finally, the overall data in the literature suggest that shell shape variability is an important adaptive component to environmental stressors. These findings bring us back to the fact that it is difficult to summarise all the interacting factors that condition shell shape. It would therefore be judicious to overlay our results on the population density and predation pressure of this species. 


\section{Conclusions}

The combined use of metric measurements, environmental factors monitoring and titrimetric assay made it possible to describe shell shape variation in $M$. galloprovincialis from Moroccan Atlantic coasts and its implications. Therefore, despite the similarity of the results between the 2 sites concerning $\left[\mathrm{Ca}^{2+}\right]$, it would seem that the shell deformation in individuals from Jorf-Lasfar site is related to environmental factors reflecting the effect on assimilation of a greater bioconcentration of calcium ions. This situation has a serious impact on the morphometry of the shells, which tend to gain in thickness and lose in width, thus marking the appearance of the deformation. In order to protect wild mussel beds of $M$. galloprovincialis, and to preserve the shoreline of El jadida region, further studies are needed to determine the relationship between the effects of industrial pollution on bivalve shell calcium ion concentration.

\section{References}

[1] R Beiras. Marine pollution: Sources fate and effects of pollutants in coastal ecosystems. Elsevier, Amsterdam, Netherlands, 2018, p. 293-311.

[2] N Talib, J Sif, A Chemaa and H Thomas-Guyon. Bioaccumulation des métaux lourds ( $\mathrm{Hg}, \mathrm{Cd}, \mathrm{Cu}$, $\mathrm{Zn}$ et $\mathrm{Pb}$ ) par la moule Mytilus galloprovincialis du littoral d'El Jadida (Maroc). Notes et Mémoires du Service Géologique 2007; 516, 121-6.

[3] M Merzouki, N Talib and J Sif. Indice de condition et teneurs de quelques métaux $(\mathrm{Cu}, \mathrm{Cd}, \mathrm{Zn}$ et $\mathrm{Hg}$ ) dans les organes de la moule Mytilus galloprovincialis de la côte d'El Jadida (Maroc) en mai et juin 2004. Bulletin de l'Institut Scientifique, Rabat, section Sciences de la Vie. 2009; 31, 21-6.

[4] K Amine, S Jamila, B Nezha and EH Hicham. Persistent organic pollutants in Mytilus galloprovincialis mussel from El Jadida coast (Atlantic coast, Morocco). Int. J. Latest Res. Eng. Manag. Res. 2020; 5, 1-6.

[5] J Sif, A Khalil, H Abouinan, A Rouhi and K Mokhliss. Effects of phtalates on the biology of the mussel Mytilus galloprovincialis (from the Atlantic Coast of El Jadida, Morocco). J. Xenobiot. 2016; 6: 6589.

[6] K Amine, S Jamila, M Khadija and EH Hicham. Estimated growth of the Mediterranean mussel Mytilus galloprovincialis from a polluted natural environment in Atlantic coast of Morocco. Int. J. Ecol. Sci. Environ. Eng. 2019; 6, 1-8.

[7] R Seed and CA Richardson. Mytilus growth and its environmental responsiveness. In: GB Stefano (Ed.). The neurobiology of Mytilus edulis. Manchester University Press, Manchester, 1990, p. 1-37.

[8] MC Dove and J Sammut. Impacts of estuarine acidification on survival and growth of Sydney rock Oysters Saccostrea glomerata (Gould 1850). J. Shellfish Res. 2007; 26, 519-27.

[9] SC Fitzer, L Vittert, A Bowman, NA Kamenos, VR Phoenix and M Cusack. Ocean acidification and temperature increase impact mussel shell shape and thickness: Problematic for protection? Ecol. Evol. 2015; 5, 4875-84.

[10] J Beldowski, A Loffler, B Schneider and L Harkonen. Distribution and biogeochemical control of the total $\mathrm{CO}^{2}$ and total alkalinity in the Baltic Sea. J. Mar. Syst. 2010; 81, 252-9.

[11] CA Frieder, SL Applebaum, TCF Pan, D Hedgecock and DT Manahan. Metabolic cost of calcification in bivalve larvae under experimental ocean acidification. ICES J. Mar. Sci. 2016; 74, 941-54.

[12] N Kautsky, K Johannesson and M Tedengren. Genotypic and phenotypic differences between Baltic and North Sea populations of Mytilus edulis evaluated through reciprocal transplantations. I. Growth and morphology. Mar. Ecol. Prog. Ser. 1990; 59, 203-10.

[13] U Kossak. 2006, How climate change translates into ecological change: Impacts of warming and desalination on prey properties and predator-prey interactions in the Baltic Sea. Ph. D. Thesis. Christian Albrechts University, Kiel, Germany.

[14] T Sanders, L Schmittmann, JC Nascimento-Schulze and F Melzner. High calcification costs limit mussel growth at low salinity. Front. Mar. Sci. 2018; 5, 352.

[15] Haut Commissariat au Plan: Regional monography of Doukala-abda, Available at: https://hcp.ma, accessed June 2021.

[16] ISO 6058:1984, Water quality - Determination of calcium content - EDTA titrimetric method, Available at: http://iso.org, accessed January 2020.

[17] AR Lucas and CA Rangel. Detection of the first larval feeding in Crassostrea gigas using the epifluorescence microscope. Aquaculture 1983; 30, 369-74. 
[18] SM Cragg. The adductor and retractor muscles of the veliger of Pecten maximus (L.) (Bivalvia). $J$. Mollus. Stud. 1985; 51, 276-83.

[19] L Telesca, K Michalek, T Sanders, LS Peck, J Thyrring and EM Harper. Blue mussel shell shape plasticity and natural environments: A quantitative approach. Sci. Rep. 2018; 8, 2865.

[20] J Thyrring, S Rysgaard, ME Blicher and MK Sejr. Metabolic cold adaptation and aerobic performance of blue mussels (Mytilus edulis) along a temperature gradient into the High Arctic region. Mar. Biol. 2015; 162, 235-43.

[21] J Orr, VJ Fabry, O Aumont, L Bopp, SC Doney, RA Feely, A Gnanadesikan, N Gruber, A Ishida, F Joos, RM Key, K Lindsay, E Maier-Reimer, R Matear, P Monfray, A Mouchet, RG Najjar, GK Plattner, KB Rodgers, CL Sabine, JL Sarmiento, R Schlitzer, RD Slater, IJ Totterdell, MF Weirig, Y Yamanaka and A Yool. Anthropogenic ocean acidification over the twenty-first century and its impact on calcifying organisms. Nature 2005; 437, 681-6.

[22] KJ Kroeker, RL Kordas, R Crim, IE Hendriks, L Ramajo, GS Singh, CM Duarte and JP Gattuso. Impacts of ocean acidification on marine organisms: Quantifying sensitivities and interaction with warming. Glob. Change Biol. 2013; 19, 1884-96.

[23] F Gazeau, LM Parker, S Comeau, JP Gattuso, WA O’Connor, S Martin, HO Portner and PM Ross. Impacts of ocean acidification on marine shelled molluscs. Mar. Biol. 2013; 160, 2207-45.

[24] GG Waldbusser, B Hales, CJ Langdon, BA Haley, P Schrader, EL Brunner, MW Gray, CA Miller and I Gimenez. Saturation-state sensitivity of marine bivalve larvae to ocean acidification. Nat. Clim. Change 2014; 5, 273-80.

[25] J Thomsen, K Haynert, KM Wegner and F Melzner. Impact of seawater carbonate chemistry on the calcification of marine bivalves. Biogeosciences 2015; 12, 4209-20.

[26] LT Bach. Reconsidering the role of carbonate ion concentration in calcification by marine organisms. Biogeosciences 2015; 12, 4939-51.

[27] J Thomsen, K Ramesh, T Sanders, M Bleich and F Melzner. Calcification in a marginal sea influence of seawater $\left[\mathrm{Ca}^{2+}\right]$ and carbonate chemistry on bivalve shell formation. Biogeosciences 2018; 15, 1469-82. 